\title{
Notes on the taxonomy and occurrence of some species of Gyromitra in Finland
}

\author{
SEPPO HUHTINEN and JUHANI RUOTSALAINEN
}

\begin{abstract}
HUHTINEN, S. \& RUOTSALAINEN, J. 2004: Notes on the taxonomy and occurrence of some species of Gyromitra in Finland. - Karstenia 44: 25-34, 2004. Helsinki. ISSN 0453-3402.

New finds of Gyromitra longipes Harmaja have revealed that this species is more variable than earlier realized. The material previously reported as Gyromitra splend$i d a$ Raitv. from Finland is shown to be conspecific with $G$. longipes. Based on a study of a topotype from Estonia, G. splendida is shown to differ from Finnish material mainly by its clearly larger spores. The variability in the macromorphology of $G$. longipes is treated and illustrated. Both taxa are characterized by broadly folded pilei and subfusiform spores with prominent perisporium. The type of $G$. bubacii Velen. was studied and the taxon is recognized at the specific level. It is macroscopically close to typical $G$. esculenta (Pers. : Fr.) Fr. with clearly gyrose pilei. The variability of $G$. esculenta in its spore characteristics is also treated. Colour photographs of $G$. longipes and $G$. splendida are provided.
\end{abstract}

Key words: Gyromitra, taxonomy

Seppo Huhtinen, Herbarium, University of Turku, FI-20014 Turku, Finland

Juhani Ruotsalainen, Metsätie 12 A4, FI-71310 Vehmersalmi, Finland

\section{Introduction}

Harmaja (1979a, 1979b) discussed the variability of Finnish specimens of Gyromitra esculenta (Pers. : Fr.) Fr. coll., recognizing three types mainly on spore characteristics. Type I, possessing ellipsoid spores with less pronounced perisporium, was treated as G. esculenta s. str. Typically, most spores are lacking a perisporium and if present, it reaches only $0.5 \mu \mathrm{m}$ in thickness at spore ends. Type II was characterized by dominance of subfusiform spores, almost all of which were stated to have a perisporium reaching $0.3-$ $1.0 \mu \mathrm{m}$ at spore ends. This type was not given any taxonomic name. Type III was treated as $G$. splendida Raitv., with fusiform to subfusiform spores and with perisporial spore ends measuring $0.6-1.5 \mu \mathrm{m}$ in thickness. Oil drops in spores were reported (in MLZ = Melzer's reagent) to show differences in diameter; they are smallest in the Type I and larger in the other types. The Type III was also reported to have a slightly longer stipe than in the other two types (Harmaja 1979a).

In a separate paper (Harmaja 1979b), a macromorphologically different collection was reported as a new species, G. longipes Harmaja. It was mainly compared to G. ambigua (P. Karst.) Harmaja, but also to the G. esculenta aggregate, from which $G$. longipes was distinguished by darker pileus, fairly distinctly violaceous stipe, much wider paraphysis tips and larger oil drops in spores. Although not univocally stressed by Harmaja (1979b), the broadly folded pileus and the lack of gyrose habit were recognized as macroscopic differences from $G$. esculenta. This is obvious from his comparison of the type to $G$. ambigua with a similar, non-gyrose pileus. 
More material of $G$. longipes has since been collected in Finland. Problems in naming a recent collection made by the second author (K. \& J. Ruotsalainen 5933F) revealed the need to re-examine all the relevant material. Therefore, the types of $G$. longipes, G. splendida (topotype studied) and G. bubacii Velen. (mentioned as a possible name for Type III by Harmaja 1979a) were restudied. In addition to the above mentioned JRcollection, the new material consists of one specimen of $G$. longipes and one determined as $G$. splendida, kindly sent for study by Dr. Harmaja.

\section{Methods}

The observations discussed below are based on a light microscope study of spores using lactic acid, Cotton blue (CB) and Congo red (CR) as reagents. Paraphyses were studied in $10 \% \mathrm{KOH}$. All drawings were made in $\mathrm{CB}$ with a camera lucida, unless otherwise indicated. All spore measurements were made in CB excluding perisporium. Spores were measured at random. All spore sizes, numerical or illustrated, include $90 \%$ of the total variability. $5 \%$ of maximal and minimal values are excluded, but occasional maximal values are given in parentheses.

\section{Gyromitra longipes Harmaja}

In 1979 Harmaja published G. longipes with a photograph of dried specimens well worthy of the specific epithet. In addition to the type specimen, the authors also studied a more recent collection by Harmaja from Finland. Both collections were soon realized to be a perfect match to what had been collected by the second author JR (Fig. 1). On the basis of these three collections, G. longipes is without doubt a clearly recognizable taxon. In the field it is recognized by the gently folded pileus on top of a long stipe. Another recent collection from Norway was reported by Carlsen and Stensrud (2003), with exactly the same morphology to the above mentioned Finnish material. They illustrated a long-stiped fruitbody topped by a broadly folded pileus. Judging from the excellent photograph, the fungus presented as $G$. esculenta from Japan by Imazeki et al. (1998) might also be $G$. longipes.

However, problems in Finnish material arouse we tried to delimit the specimens earlier recognized as G. splendida by Harmaja (1979a). Ap-

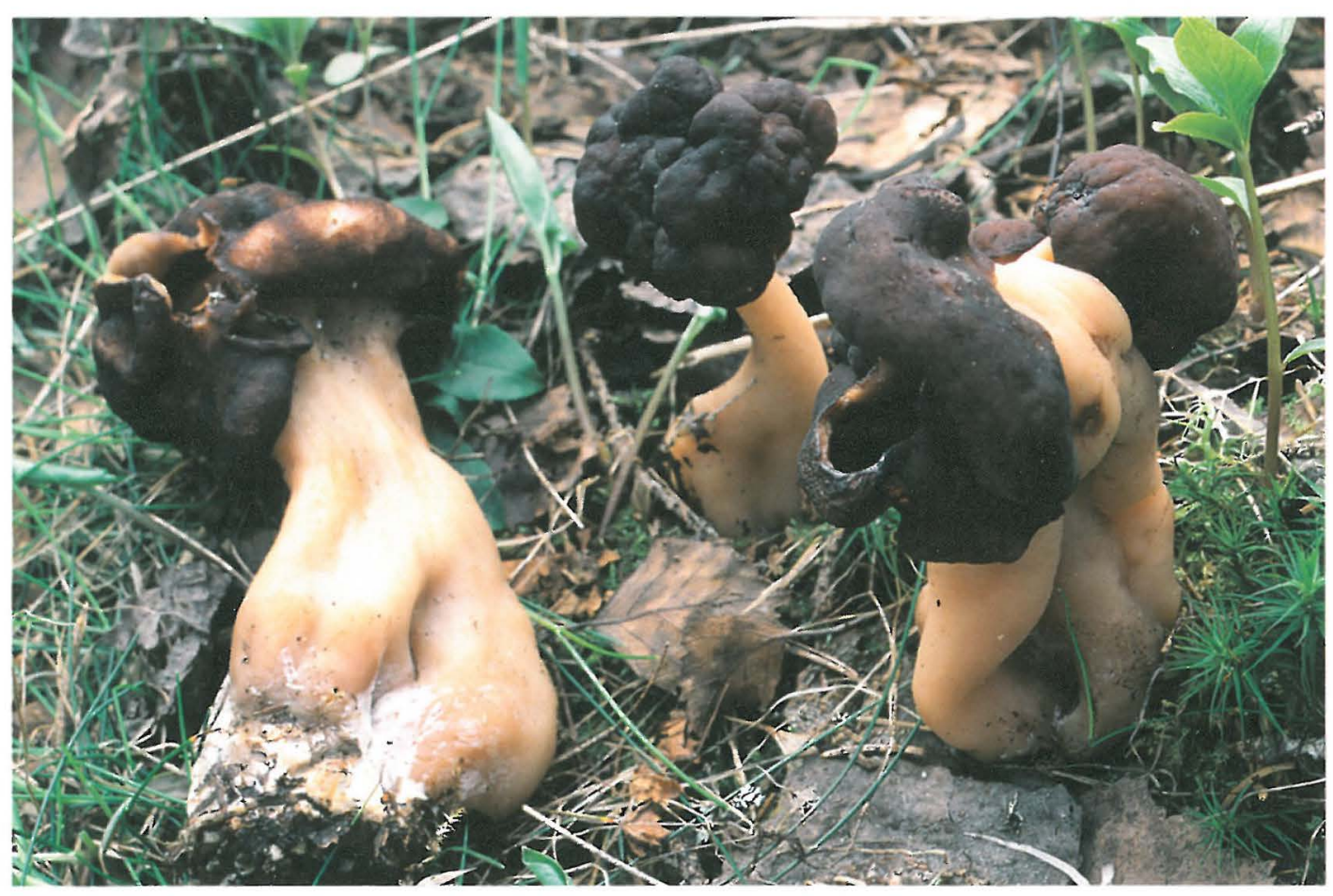

Fig. 1. Gyromitra longipes, Vehmersalmi 13.V.2002. Photo J. Ruotsalainen. 

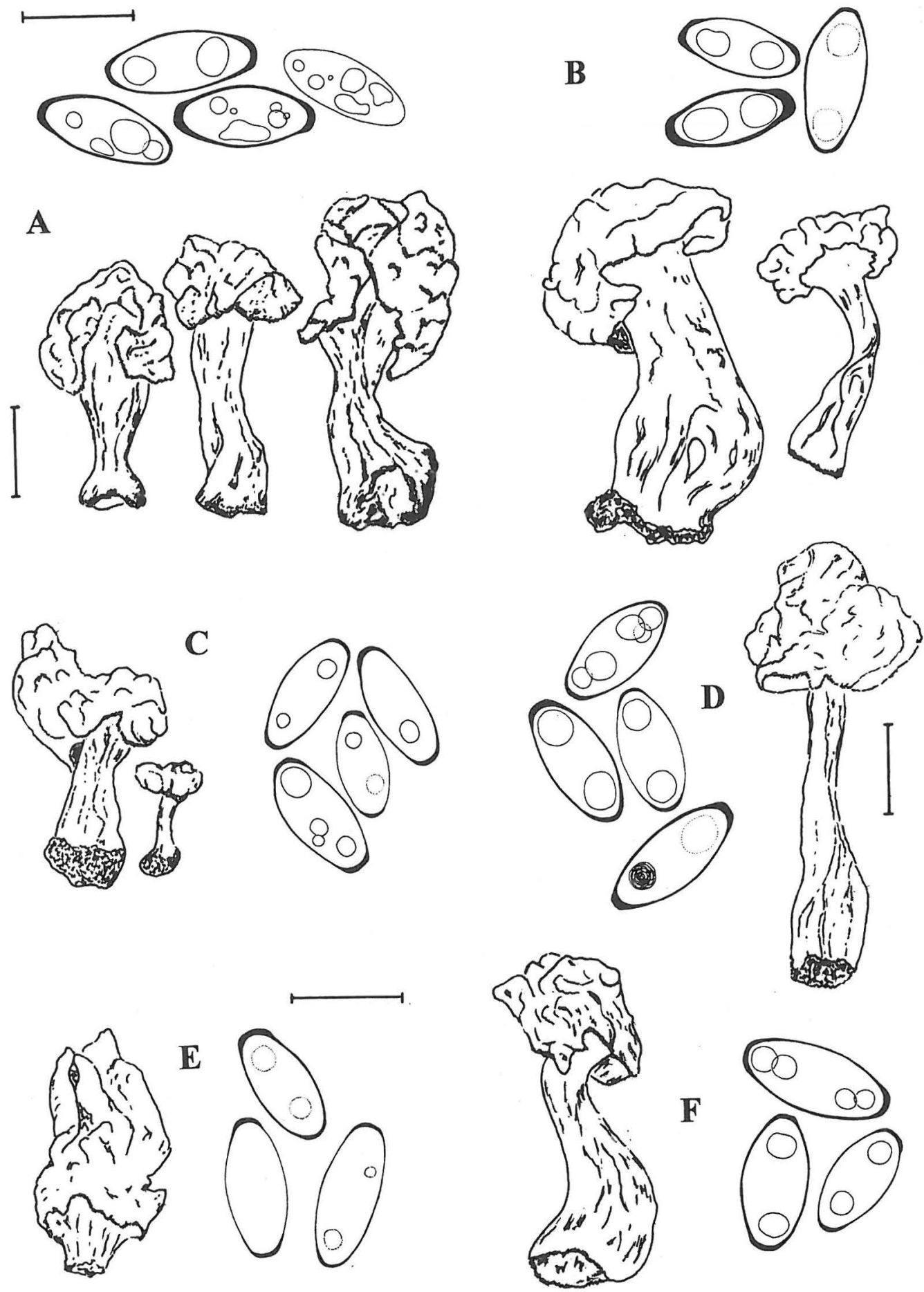

Fig. 2. Dried fruitbodies and spores of Gyromitra longipes. - A) type. - B) K. \& J. Ruotsalainen 5933F. - C) Harmaja 1977 (sub splendida). - D) Harmaja 1996 (sub longipes). - E) Uotila 24969 (sub splendida). - F) Ohenoja 9.VI.1986 (sub splendida). Scale for apothecia $2 \mathrm{~cm}$, for spores $20 \mu \mathrm{m}$. 
parently the striking habit in the type of G. longipes led Harmaja (1979b) to treat this specimen as a clear-cut species and at the same time suspect that the Type III (= G. splendida sensu Harmaja 1979a) is only a race. Harmaja noted, however, that stipes in these other collections were slightly longer than in G. esculenta. When dry, all six collections form a continuum not easy to break in a logical manner even when using macromorphology only (Fig. 2). The colouring of hymenium and the colour hues on stipe are a good match. All specimens are lacking a clearly gyrose pileus and have a crispy texture, untypical for dry specimens of G. esculenta. Pileus shape shows some difference: in one collection the sole apothecium is almost bilobate (Fig. 2E). But as a whole, stipe length and prominence seems to be the main variable character between the collections. The far ends of this variability look admittedly quite different.

This observation led us to have a closer look on spore variability. As can be seen from Fig. 3, the type specimen shows the smallest spores in the three macroscopically identical, "typical" $G$. longipes specimens. Thus, macromorphology binds together both the "untypical" spores of the type and the larger spores of later collections. When total spore variability of these three specimens is plotted together with material of G. splendida sensu Harmaja, the distributions and means are almost identical (Fig. 4). Hence, identical spores bind together the variability in stipe length and prominence. As also paraphyses are alike, we feel that Harmaja's G. splendida -material is conspecific with G. longipes. The true G. splendida remains to be found from Finland. Ryman and Holmåsen (1984) cited several Swedish specimens with splendida -type spores, but since spore size was not given, the conspecifity with the type of G. splendida needs to be rechecked.

\section{Gyromitra splendida Raitv.}

This species was described on the basis of one collection from Estonia (Raitviir 1974). The given differences from G. esculenta are distinct. Macroscopically $G$. splendida has darker colour of stipe and hymenium and the long stipe is bearing a relatively narrow cap. Hymenial colour was described as dark brown to almost blackish brown and stipe as ochraceous to fulvous with fleshy tinge. Raitviir's spore drawings show clearly the drastic difference in spore shape when compared to G. esculenta. On the other hand, Raitviir admitted the presumed overlap in macromorphology by stating that " $G$. splendida occurs in the same habitat as G. esculenta and is superficially so similar to it that they might be easily confused macroscopically." We received an unpublished colour slide of G. splendida from Dr. Raitviir, which strengthened our view that in the field one should pay attention especially to the gently fold-

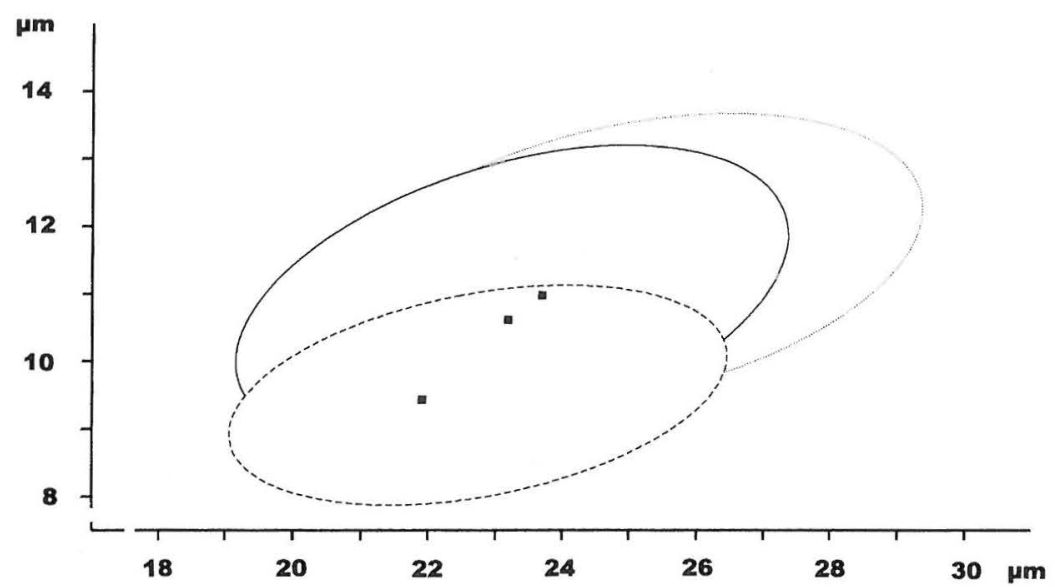

Fig. 3. Spore variability and average sizes in three morphologically typical specimens of Gyromitra longipes. Holotype (broken line, $\mathrm{n}=100$ ), $K . \& J$. Ruotsalainen 5933F (even line, $\mathrm{n}=100$ ), Harmaja 1996 (dotted line, $\mathrm{n}=100$ ). 


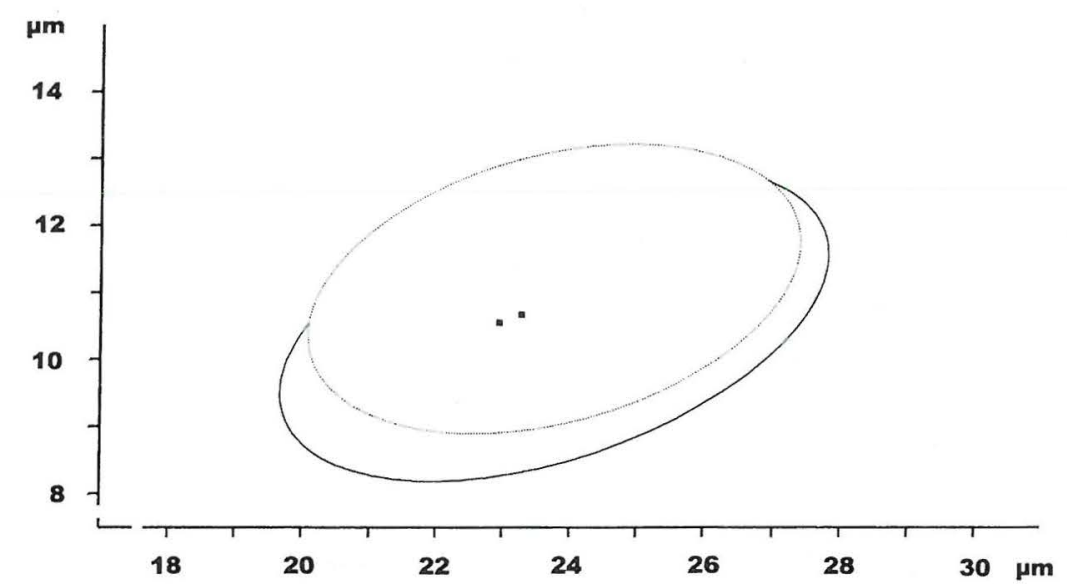

Fig. 4. Spore variability and average sizes in three specimens of $G$. longipes (even line, $\mathrm{n}=300$ ) and three specimens of $G$. splendida sensu Harmaja (dotted line, $\mathrm{n}=100$ ).

ed hymenium. This photo was taken two years after the type collection, representing a topotype, from which we also received pieces of hymenium for study. The typical clearly gyrose habit of G. esculenta is lacking. Raitviir's photo (our Fig. 5) deviates somewhat from the holotype specimen in showing a relatively short stipe together with broad cap. This variability is discussed further below. However, it is clear that Raitviir published a taxon which is clearly separate from G. esculenta.

The material reported and determined as G. splendida from Finland differs from the type in spore size. The spores are of similar shape, they have a similarly pronounced perisporium surrounding the whole spore. Oil globules are also prominent. The spore size distribution and spore mean size separate the material into two entities. The topotype specimen has a mean spore size value of $27.7 \times 11.7 \mu \mathrm{m}(\mathrm{n}=100)$. The three Finnish specimens have a mean value of $23.3 \times$ $10.6 \mu \mathrm{m}(\mathrm{n}=100)$ and they show the following individual means: $22.8 \times 11.4 \mu \mathrm{m}, 21.7 \times 9.6 \mu \mathrm{m}$ and $24.4 \times 10.1 \mu \mathrm{m}$. As seen from spore drawings, their shape and general appearance is identical (Fig. 2C, 2E, 2F and Fig. 6B).

The spore size range in the topotype is wide: $23.5-32.2(-35.0) \times 10.6-13.5(-15.0) \mu \mathrm{m}(\mathrm{n}=$ 100 ). These figures differ slightly from those given in the original diagnosis. For Finnish specimens (under $G$. splendida) the size range is following: $21.0-26.6 .(-30.8) \times 9.5-12.2(-13.5) \mu \mathrm{m}$ $(n=100)$. Difficulties arise due to the differencies in hymenium age. It is possible that the spores reach their maturity extremely slow. Both in the type and the other studied specimens all free spores are $\mathrm{CB}+$. The presence of a continuous perisporium does not univocally prove their more or less similar developmental stage. Differency in spore size seems to be the main distinguishing character, the type of G. splendida possibly representing a fully mature collection. Fruit-body size

Fig. 5. Gyromitra splendida, topotype in situ. Photo: A. Raitviir.

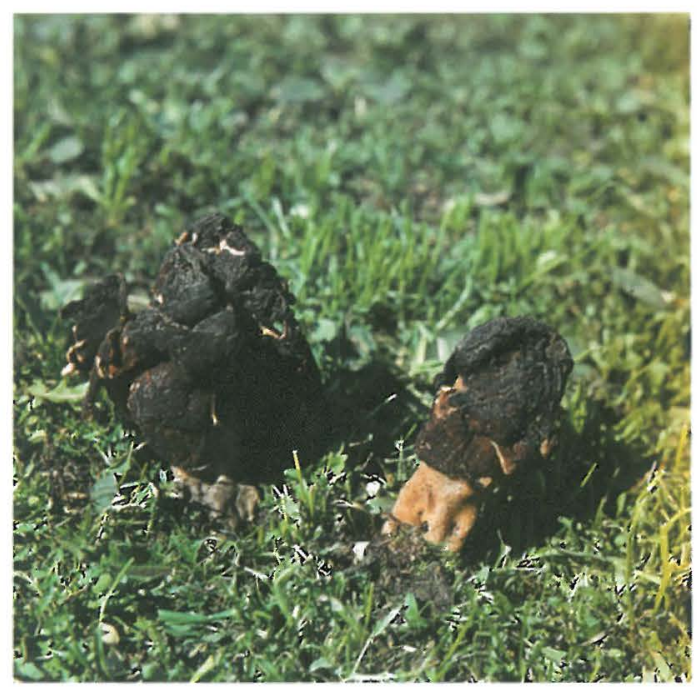



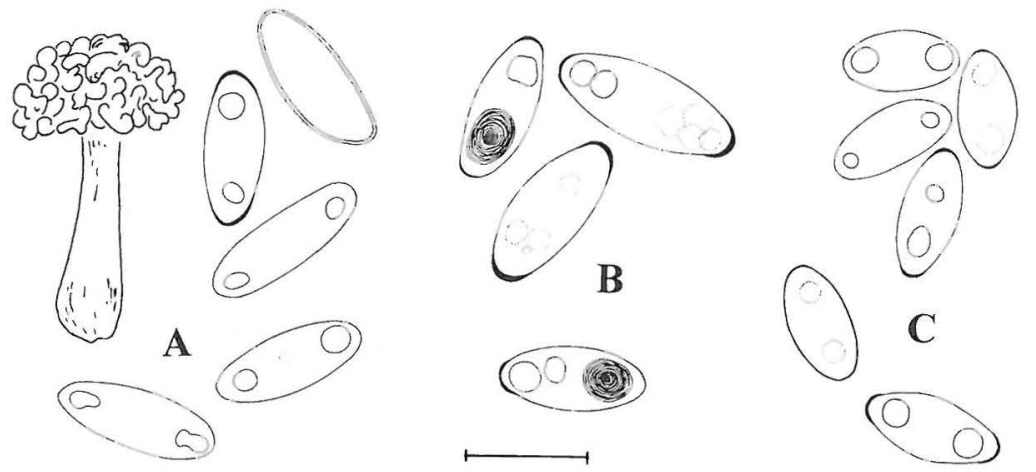

Fig. 6. Gyromitra spores. - A) type of G. bubacii, fruitbody redrawn from Velenovský (1934), scale unknown. - B) topotype of G. splendida. - C) "Type II" of G. esculenta, Hintikka 1962. Scale: $20 \mu \mathrm{m}$.

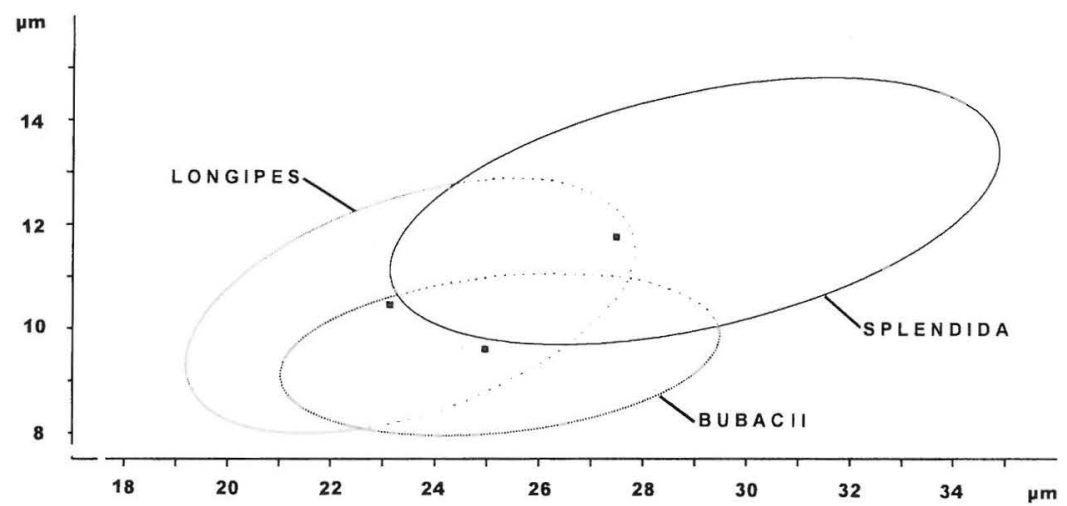

Fig 7. Spore variability and average sizes in three species of Gyromitra. G. longipes is represented by the whole Finnish material $(n=400)$ and the other two by their type specimens $(n=100$ for both).
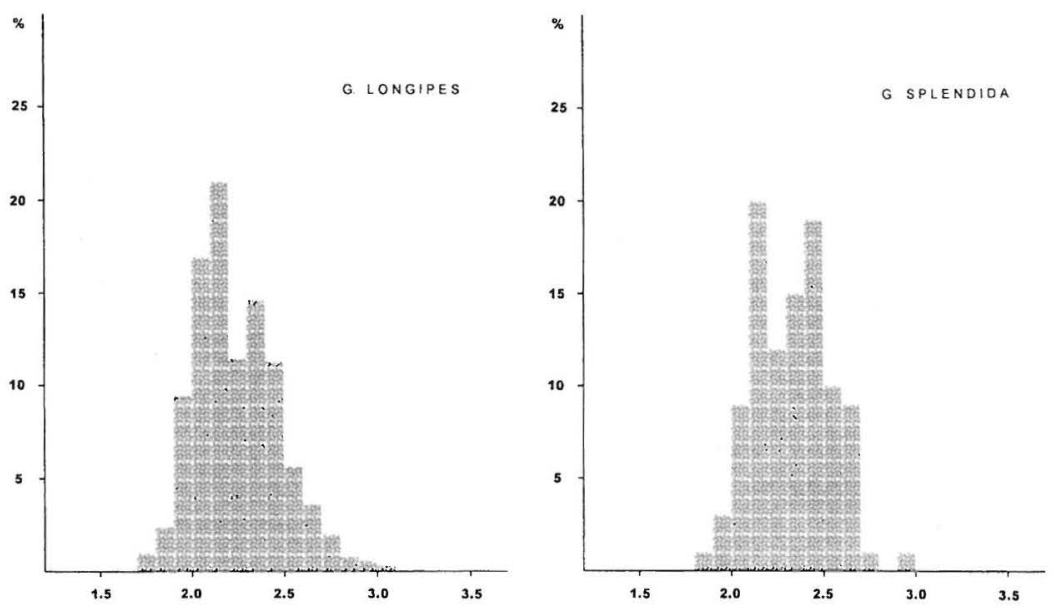

Fig. 8. The distribution of spore Q-values in two species of Gyromitra ( $\mathrm{n}=400$ for longipes and $\mathrm{n}=100$ for splendida). 
given in the original diagnosis shows, however, that type material has not been clearly larger than the Finnish collections. We have not seen full fruitbodies. But even from the pieces the broadly folded pileus and the crispy texture are obvious. A comparison of paraphyses from all collections revealed no differencies between the type of $G$. splendida and Finnish material.

As seen in Fig. 7, the Finnish specimens clearly differ in spore size from the topotype of $G$. splendida, whereas the distributions of $\mathrm{Q}$-values are alike (Fig. 8). The most recent collection from Vehmersalmi contained fruit-bodies which were mature to partly overmature. Hence, at least their spore size reflects the size of fully mature spores. Unless intermediate material is collected, one can only state that $G$. splendida is a different taxon, known only from the type locality in Estonia. Should there later prove out to be a continuum in spore size, G. longipes would fall into synonymy of $G$. splendida.

\section{Gyromitra bubacii Velen.}

The species was described in Ćeské houby (Velenovský 1922) based on one collection, which was later illustrated by Velenovský (1934). The type was preserved in formaldehyde solution and later dried. Due to Velenovský's plate showing a long-stiped fungus, here redrawn in Fig. 6A, part of the type was restudied. Harmaja (1979a) tentatively hinted on $G$. bubacii being an earlier name for G. splendida, but he did not study the types. Thereafter, the type of Velenovskýs species has been studied twice (Moravec 1986, Abbott \& Currah 1997).

Moravec compared the spores of the type to a large material collected as $G$. esculenta mainly from Bavaria and Slovakia. He came to the conclusion that $G$. bubacii can be recognized only as a variety of $G$. esculenta. Moravec found no macroscopic differences. He also stated that the spore size of typical G. esculenta quite often reaches the maximum of $29.5 \mu \mathrm{m}$ whereas $G$. esculenta var. bubacii (Velen.) J. Moravec shows a range from 20 to $35.5 \mu \mathrm{m}$, the width remaining unchanged. Judging from the text, Moravec recognized two additional collections of G. bubacii. The variety is illustrated in one plate. Comparing his notes within the type packet and the drawing, we conclude that Moravec's illustration is not from the type. His illustration shows even more inaequilateral spores than those seen in the type as illustrated here (Fig. 6A). Such spores have not been seen in Finnish material of G. esculenta. To us they represent a clear-cut difference to all other Gyromitras treated in this paper.

Abbott and Currah (1997) listed G. bubacii as a synonym of $G$. esculenta and commented on Harmaja's (1979a) three spore types in this complex. They studied the type of Velenovský's species and noted the large spores, but erroneously concluded that $G$. esculenta would be a continuum of uncorrelated characters. For them the dif-

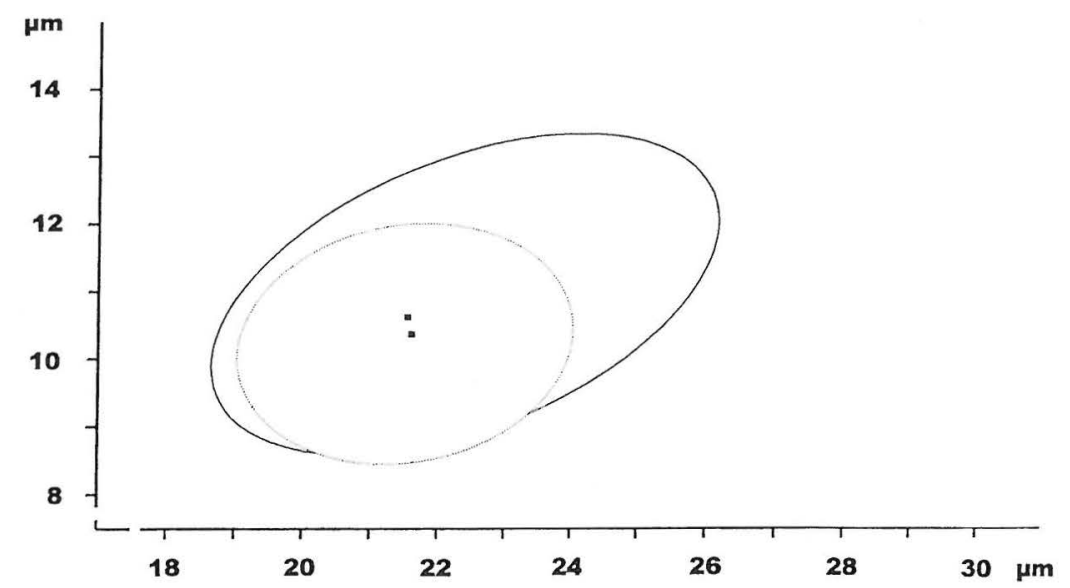

Fig 9. Spore variability and average sizes in G. esculenta s. str. (even line, $\mathrm{n}=100$ from 11 populations) and $G$. esculenta "Type II" (broken line, $\mathrm{n}=100$ from 1 population). 


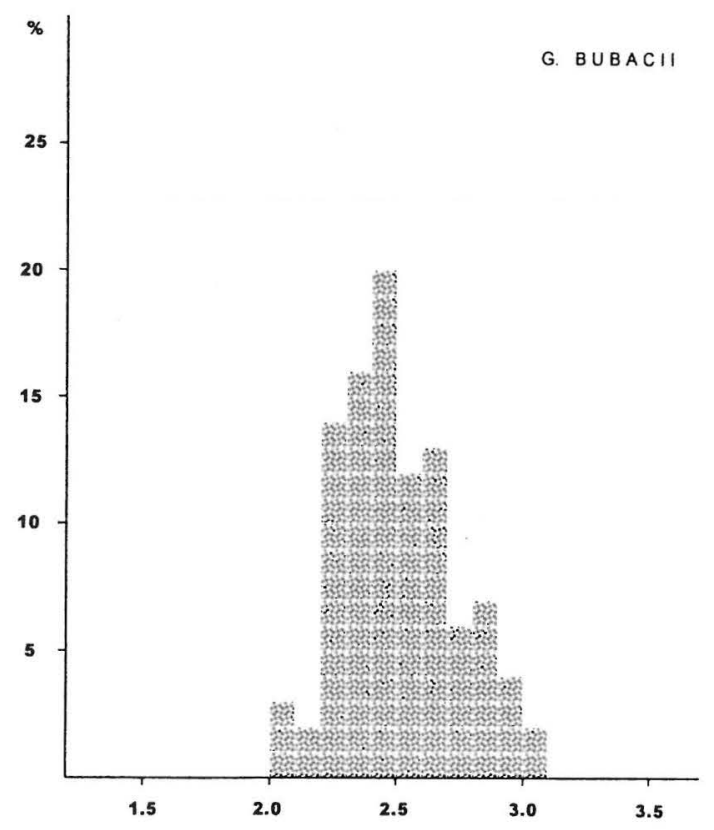

Fig. 10. The distribution of spore Q-values in the type specimen of Gyromitra bubacii $(\mathrm{n}=100)$. ferences between the cylindrical - ellipsoid -inequilateral spores of the type lacking prominent apiculi and the ellipsoid -subfusiform spore of Type III depicted by Harmaja - passed unnoticed. To us, exactly here lie the marked differences (compare Fig. 7 and Fig. 9).

A study of a random selection of Finnish specimens of typical and mature $G$. esculenta gave results somewhat different from those by Moravec (1986). Randomly measured spores show a mean of $21.7 \times 10.7 \mu \mathrm{m}(\mathrm{n}=100$, from 11 populations) and the range of $20.0-24.6 \times 9.6-11.7 \mu \mathrm{m}$. The mean spore quotient was 2.03 . Our random measurements from the type of $G$. bubacii gave the mean of $24.9 \times 9.7 \mu \mathrm{m}(\mathrm{n}=100)$ and the range of $21.4-28.0(-30.8) \times 8.8-10.6(-11.0) \mu$ m. Mean spore quotient was 2.61 . The clear difference in the distribution of Q-values can be seen in Fig. 10 and Fig. 11. The spores of G. bubacii have a continous, but very thin perisporium. The perisporium may have suffered from formaldehyde solution but was still present in type material. Moravec (1986) did not observe or illustrate any apiculi in recent material (not preserved in formaldehyde); hence the apiculi illustrated in Fig. 6A apparently represent the maximum for this species.
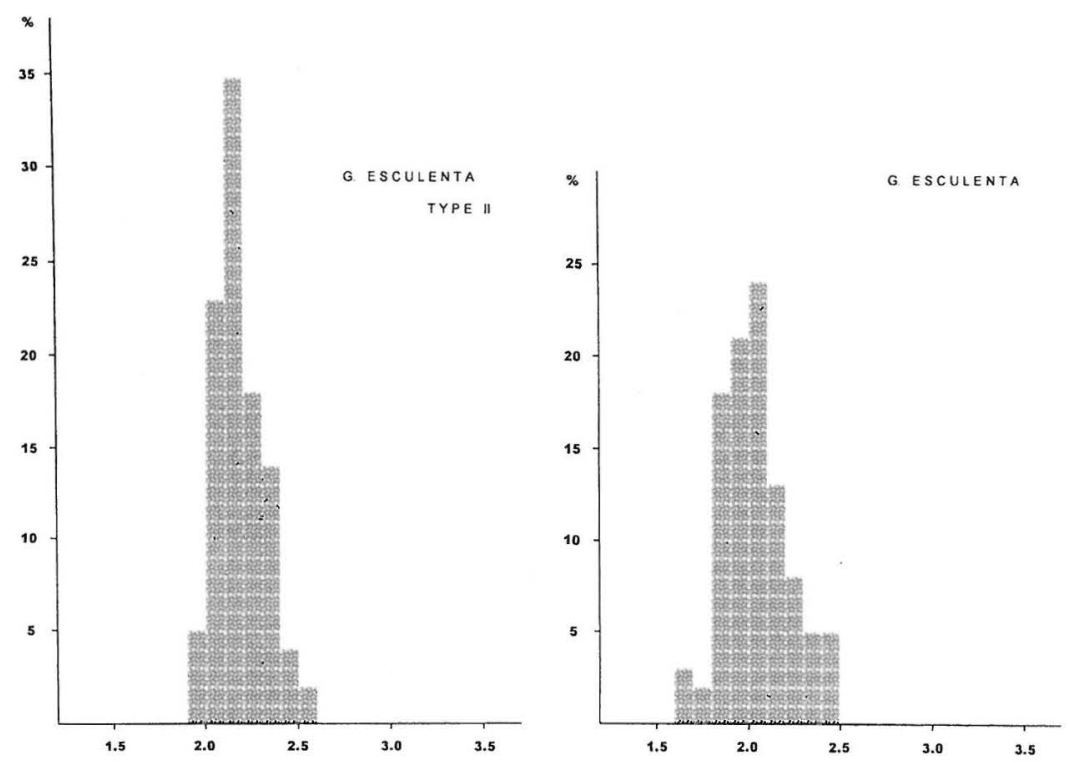

Fig. 11. The distribution of spore Q-values in G. esculenta s. str. $(\mathrm{n}=100)$ and G. esculenta "Type II" $(\mathrm{n}=100)$ 


\section{Gyromitra esculenta, spore type II}

We also received one collection from $\mathrm{H}$, which was determined by Dr. Harmaja as "Type II". This collection showed tough consistency and gyrose pileus and was macroscopically similar to material of G. esculenta. As noted by Harmaja (1979a), spore shape varies from ellipsoid to fusiform. "Type II" was defined to embrace populations where most spores are subfusiform.

Our observations from comparing 11 populations of typical G. esculenta with the sole available collection of "Type II" revealed only a very slight difference in mean spore quotient: for "Type II" it was 2.08 ( $\mathrm{n}=100$, one population) and for $G$. esculenta 2.03 ( $\mathrm{n}=100,11$ populations). A comparison of the total distribution of Q-values in both types shows a slight difference. In "Type II" the lowest Q-values from 1.6 to 1.8 are totally lacking and in G. esculenta, $23 \%$ of the randomly measured spores belong to this more ellipsoid type (Fig. 11). From Fig. 9 it is obvious that there is no true difference in spore size. From Fig. 6C one can see the maximal prominence of apiculi in "Type II", which is the same as illustrated by Harmaja (1979a). The interpopulational difference pointed out by Harmaja (1979a) seems to be present, but like he we also are unable to weigh the taxonomic level and value of this difference. We found two additional Finnish collections, coming close to this spore type, the other collection with mean Q-value of 2.17.

\section{Gyromitra longipes in fresh}

The most recent collection from Finland was made during a regular collection trip for false morel. The specimens were first collected as somewhat atypical, less folded and fragile G. esculenta. When spore differences were recognized by JR, also the macromorphological differencies became more clear. Gyromitra longipes has a hymenium which is not shiny as it is in false morel. The material from Vehmersalmi was abundant, in all 40 fruitbodies. The matt hymenium and gently folded pileus were characteristic for all of them. In fresh condition the fragrant texture, also typical for dried specimens, was obvious. The hymenium was also characterized by small areas where the whole ascal layer was eroded and the light inner excipulum was exposed. The odour was also recorded from fresh material. Carlsen and Stensrud (2003) reported the odour to be spermatic for Norwegian material. In material from Vehmersalmi the odour was clearly less esculenta-like (often also characterized as "spermatic") than in typical esculentas. The odour was noted by two persons to be less prominent and to have a pleasant component, originally noted to be somewhat close to the odour of Boletus edulis.

A single, interesting case of variability in pileus structure was recently reported by Kosonen (2003). Amongst hundreds of normal fruitbodies of Gyromitra infula (Schaeff. : Fr.) Quel. He found one fruitbody showing the typical clearly gyrose pileus of G. esculenta. This is the first reported case from Finland. It seems that variability from gyrose to less gyrose (as in G. esculenta) is much more common than typically folded pilei being clearly gyrose. But nevertheless, $G$. longipes can be recognized in the field even when the prominence of stipe does not match the epithet.

In Vehmersalmi the population was collected in a small clear-cut area, which had been mechanically treated by ploughing and removal of stumps. Some of the fruit-bodies were found in an adjoining, only partially cut stand. The cutting was made in a mesic, mixed spruce forest. The intermixed trees were aspens and birches. In all, the site was not considered as particularly lush. From the label data of other Finnish collections of $G$. longipes the ecological amplitude seems to embrace the following: (1) old and rich mixed spruce forest with Betula, Populus, Tilia, Lonicera, Ribes alpinum and Lathyrus vernus, (2) clear-cut in a mixed spruce and pine forest with Vaccinium myrtillus and $V$. vitis-idaea, (3) mixed, mesic spruce forest with Betula, Oxalis, Vaccinium myrtillus, (4) mesic heath forest with Picea, Pinus, Alnus incana and Betula, and (5) dry spruce and pine forest in a calcareous area. In all but one collection, the fruitbodies were found in a site where the mineral soil was more or less exposed. The soil seems to vary from sand to till. 
Material studied: Gyromitra longipes. Finland. EteläHäme. Hattula, Mervi, Parolanharju, Marttaristi, 6.VI.1976 Uotila 24969 (H, sub. G. splendida). Lammi, Jahkola, 22.V.1977 Harmaja (H, sub. G. splendida). Lammi, Porkkala, Mustasuppa, 9.VI.1996 Harmaja (H, sub. G. longipes). Virrat, Hauhuu, 22.V.1979 Kytövuori 4179 (H, holotype of $G$. longipes). - PohjoisSavo. Vehmersalmi, Räsälä, Pajumäki, 11-13.V.2002 $K$. \& J. Ruotsalainen $5933 F$ (KUO, TUR). - PeräPohjanmaa. Tervola, Könölä, Yli-Paakkola, Torniokumpu, 9.VI.1986 Ohenoja (H, sub. G. splendida).

Gyromitra splendida. Estonia. Viljandimaa. Soomaa National Park, Iia between Kõpu and Tipu, 10.V.1975 Raitviir (TAA, topotype of G. splendida).

Gyromitra bubacii. Czech Republic. Dobrís, 15.V.1921 Jedlicka (PRC, holotype of G. bubacii).

Gyromitra esculenta, spore type II. Finland. Varsinais-Suomi. Paimio, Epistenkylä, 23.V.1973 Alho (TUR). - Perä-Pohjanmaa. Rovaniemi rural parish, Sinettä, 16.VI.1968 A. \& K. Pohjola (TUR). USA. Michigan. Ogemaw County, 6.V.1962 Hintikka (H, det H. Harmaja).

Gyromitra esculenta s. str. Finland. Varsinais-Suomi. Kemiö, Norrlângvik, Långsandabacken, 3.V.1990 Alho (TUR). Koski, Liipola, 7.VI.1998 M.-L. \& P. Heinonen 272/1998 (TUR). Mietoinen, Mynäjoen metsätie, 1.VI.1973 Alho (TUR). Mynämäki, 27.V.1969 Pohjola (TUR). Parainen, Lenholm, 17.V.1995 M.-L. \& P. Heinonen 108/95 (TUR). Sauvo, 28.V.1967 Mäkinen 67/44 (TUR). Uusikaupunki, Kalanti, Vellua, 7.V.1989 Alho (TUR). - Perä-Pohjanmaa. Ylitornio, Meltosjärvi, 17.VI.1968 A. \& K. Pohjola (TUR). Rovaniemi rural parish, Pokka, 19.VI.1968 A. \& K. Pohjola (TUR). Sompion Lappi. Sodankylä, Kakslauttanen, 30.VI.1965 Mäkinen (TUR). - Inarin Lappi. Ivalo, 15.VII.1968 Mäkinen 68/261 (TUR).

Acknowledgements: The staffs of the herbaria in Helsinki $(\mathrm{H})$ and Prague (PRC, PRM) are warmly thanked for the loan of types and interesting specimens. We also thank Dr. Ain Raitviir (Tartu) for the opportunity to study material of G. splendida and publish a colour photograph of it.

\section{References}

Abbott, S. P. \& Currah, R.S. 1997: The Helvellaceae: systematic revision and occurrence in northern and northwestern North America. - Mycotaxon 62: 1125.

Carlsen, T.A. \& Stensrud, Ø. 2003: Hattmorkelen Gyromitra longipes Harmaja funnet I Norge. - Blyttia 61: 76-78.

Harmaja, H., 1979a: Notes on Gyromitra esculenta coll. and G. recurva, a noteworthy species of western North America. - Karstenia 19: 46-49.

Harmaja, H. 1979b: Studies on vernal species of Gyromitra and Pseudombrophila (syn. Nannfeldtiella). Ann. Bot. Fenn. 16: 159-162.

Imazeki, R., Otani, Y. \& Hongo, T. (eds.) 1998: Fungi of Japan. - 624 pp.

Kosonen, L. 2003: Syksyinen korvasieni on piispanhiippa. - Sienilehti 55: 60.

Moravec, J. 1986: A revision of the type of Gyromitra bubaci and the problem of ascospore size of Gyromitra esculenta (Discomycetes) - Ceská Mykol. 40: 1118.

Raitviir, A. 1974: A new species of Gyromitra from Estonia. - Folia. Cryptog. Estonica 4: 30-31.

Ryman, S. \& Holmảsen, I. 1984: Svampar. En fälthandbok. -718 pp. Interpublishing AB, Stockholm.

Velenovský, J. 1922: Ćeské houby 4-5: 633-950. - Pragae.

Velenovský, J. 1934: Monographia Discomycetum Bohemiae 1-2. - 436 pp., 31 Tab. Sumptibus propriis, Pragae. 